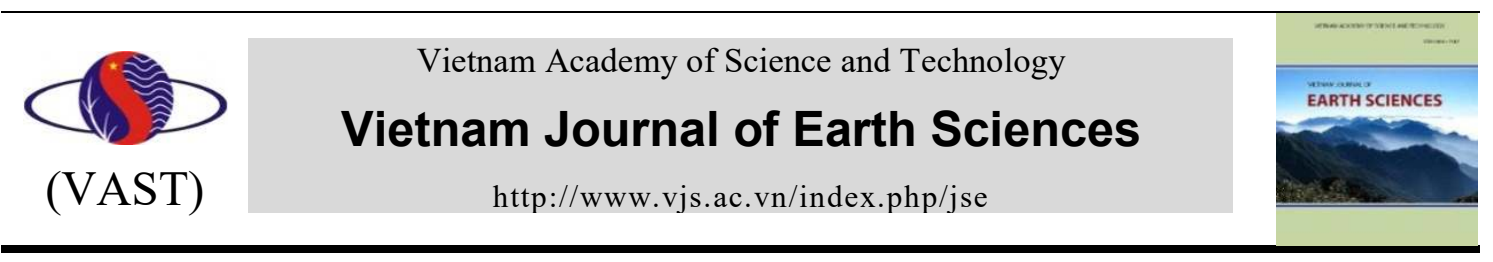

\title{
Assessment of earthquake-induced liquefaction hazard in urban areas of Hanoi city using LPI-based method
}

\author{
Bui Thi Nhung1*, Nguyen Hong Phuong1, 2, 3, Pham The Truyen"1, 2, Nguyen Ta Nam ${ }^{1}$ \\ ${ }^{1}$ Institute of Geophysics, Vietnam Academy of Science and Technology \\ ${ }^{2}$ Graduate University of Science and Technology, Vietnam Academy of Science and Technology \\ ${ }^{3} I R D$, Sorbonne Universités, UPMC Univ Paris 06, Unité Mixte Internationale de Modélisation Mathématique \\ et Informatiques des Systèmes Complexes (UMMISCO)32 Venue Henri Varagnat, 93143 Bondy Cedex, France
}

Received 8 August 2017; Received in revised form 9 December 2017; Accepted 11 December 2017

\begin{abstract}
Liquefaction Potential Index (LPI) is used as an assessing tool of liquefaction potential. In this study, the LPIbased method was applied to evaluate the earthquake-induced liquefaction potential for the urban area of Hanoi city. The data used includes 120 boreholes logs, containing necessary geomechanical information such as fine contents, specific gravity, dry density, porosity, N (SPT) values and the groundwater depth Z(w) of subsoil layers in every borehole. The "simplified procedure" proposed by Seed and Idriss was applied to evaluate the liquefaction of all subsoil layers in each borehole point. Then, the Liquefaction Potential Index was calculated for the whole soil column at all boreholes points using the method proposed by Iwasaki. Finally, the obtained LPI values were used to assess the liquefaction probability for an urban area of Hanoi city, using the empirical formula proposed by Papathanassiou and two earthquake scenarios originated on the Chay River fault with magnitudes of 5.3 and 6.5 , respectively.

For entire study area, the first scenario earthquake $(\mathrm{Mw}=5.3)$ is not capable of causing liquefaction $(\mathrm{PG}<0.1)$. This means that the downtown area of Hanoi city is non-liquefiable to the medium magnitude events. Results of the second scenario $(\mathrm{Mw}=6.5)$ show in worst cases, an earthquake with magnitude, maximum expected for Hanoi region can produce liquefaction throughout the downtown area of Hanoi city. The highest liquefaction probability of $0.7<\mathrm{PG} \leq 0.9$ is distributed in two large areas, where the first one is observed in Thanh Tri district, eastern part of Ha Dong, a smaller areas of the Thanh Xuan, Tu Liem and Cau Giay districts, while the second area covers Hoan Kiem district, a northern part of Hai Ba Trung district and northwestern part of Long Bien district.

This is the first time the LPI based method was applied for evaluation of earthquake-induced liquefaction for Hanoi city. The most advantage of the method is that it can be easy to use, although the reliability of the results depends very much on number and distribution of the borehole data. Nevertheless, the combination of this method with other available methods can help effectively solving the problem of urban seismic risk assessment for the mega-cities in Vietnam.
\end{abstract}

Keywords: Liquefaction hazard; Standard Penetration Test (SPT); liquefaction potential index (LPI); liquefaction probability; earthquake.

C2018 Vietnam Academy of Science and Technology

\section{Introduction}

Liquefaction following strong earthquakes

"Corresponding author, Email: buinhung78@gmail.com is a well-known phenomenon and has been studied worldwide for a long time (Seed \& Idriss, 1971; Iwasaki 1978; 1982; Juang 2002; 2007; 2010). However, as this phenomenon 
had never been observed in Vietnam, up to now the studies of earthquake-induced liquefaction in the country are of forecasting characteristics and mostly focused on two main research directions, namely (1) assessment of liquefaction hazard for urban areas, and (2) safety evaluation of dyke systems under seismic loads.

Studies on assessment of liquefaction hazard for urban areas started in Vietnam by seismologists since the beginning of the $21 \mathrm{st}$ century. The first methodology of urban seismic risk assessment and loss estimation for Vietnam was developed in 2001 based on the HAZUS's methodology, with modification taking into account for the seismic and tectonic conditions of Vietnam and was applied to the Hoan Kiem district, a downtown district of Hanoi. In the successive years, within the national scientific research projects, the methodology has been continuously improving and applied to downtown districts of three biggest cities in the countries, namely Hanoi, Nha Trang and Ho Chi Minh city (Nguyen Hong Phuong 2002; 2003; 2008; 2009). In these studies, assessment of seismic liquefaction hazard is usually carried out as a part of the whole procedure of urban seismic risk assessment. The results of the liquefaction hazard assessment are presented in terms of maps showing the distribution of zones with different level of liquefaction susceptibility and probability under the impact of scenario earthquakes. These results then are used as input for calculation of seismic risk and loss estimation for the study areas. It should be noted that the methodology of urban seismic risk assessment deeply involves studies of such seismic characteristics of the study areas like seismicity, seismic source models, and attenuation models. In addition, wide scope of study and capability of integrating databases and research results in a GIS environment are the main advantages that make the methodology widely applicable in Vietnam.
Independently with above direction, the studies of liquefaction for safety evaluation of dyke systems have been conducted recently in Vietnam by water resource experts (Tran Dinh Hoa, 2013; Nguyen Hong Nam, 2014). The methodology applied in this study is focused on the geotechnical aspects of the problem of evaluating the liquefaction potential. However, the earthquake occurrence model, as the main cause of liquefaction, is not thoughtfully considered in this methodology. Up to now, this methodology has mostly been applied to single water resource constructions in the country.

In this paper, the idea of combining two seismic and geotechnical approaches in a procedure of earthquake-induced liquefaction hazard assessment is implemented. A method based on liquefaction potential index is used for evaluating the liquefaction hazard for the downtown area of Hanoi city. The LPI based method was applied for a study area, which is bounded by the longitudes of $105.7^{\circ} \mathrm{E} \div 106^{\circ} \mathrm{E}$ and latitudes of $20.85^{\circ} \mathrm{N} \div 21.15^{\circ} \mathrm{N}$, covering 10 downtown districts, namely Hoan Kiem, Ba Dinh, Hai Ba Trung, Dong Da, Thanh Xuan, Tu Liem, Ha Dong, Long Bien, Tay Ho, Hoang Mai and two suburb districts, namely Thanh Tri and Gia Lam of Hanoi city (see Figure 5). The realistic earthquake scenarios were developed to provide seismic input for liquefaction hazard calculation, and the results are presented in the forms of the liquefaction hazard maps compiled for the downtown area of Hanoi city.

\section{LPI-based method for evaluation of earthquake-induced liquefaction potential}

In order to evaluate the liquefaction potential of a site, Iwasaki et al., 1982 proposed the use of an index which is proportional to the thickness of the liquefiable layer, the thickness of the non-liquefiable (cap) layer and the value of the factor of safety against liquefaction (FS). Iwasaki et al., 1982 calibrated the 
values of Liquefaction Potential Index with the severity of liquefaction-induced damages using data of 87 boreholes having SPT results in liquefied and non-liquefied sites in Japan. According to this scale, liquefaction failure potential has been characterized as high where LPI ranges between 5 and 15 and low at sites where LPI ranges between 0 and 5. The liquefaction potential is extremely low where LPI is equal to 0 , while the liquefaction potential is extremely high at sites where LPI exceeding 15. The LPI scale then has been modified by various investigators for more applicability. Sonmez, 2003 proposed to add more categories of potential, namely "non-aquifeable" and "moderate" to the LPI scale. Li et al., 2006 defined the LPI as a function of the probability of liquefaction and proposed mathematical formula for estimation of the probability of liquefaction-induced ground failure.

The advantage of LPI is that it quantifies the likely of liquefaction of the site, by providing a unique value for the entire soil column instead of several factors of safety per layer. Moreover, the values of LPI can be used for the compilation of liquefaction hazard maps, which comprise a preliminary assessing tool of the liquefaction potential and can be used by decision-makers for urban planning. Up to now, the liquefaction hazard maps have been compiled for several urban areas in the world such as the city of Dhaka, Bangladesh (Ansary and Rashid 2000), the state of California, USA (Holzer et al., 2002), the town of Inegol, Turkey (Sonmez, 2003; Sonmez and Gokceoglu, 2005), the town of Eskisehir, Turkey (Koyoncu and Ulusay 2004), the city of Lefkada, Greece (Papathanassiou et al., 2005).

The deterministic procedure of LPI-based evaluation of the liquefaction potential, widely known as "the simplified procedure", was first proposed by Seed and Idriss in 1971 and has been upgraded by other investigators (Seed 1985; Youd 2001). Implementation steps of the procedure are described below in details.

\subsection{Determination of the cyclic resistance ratio (CRR)}

The CRR, according to Youd et al. (2001), is computed by the following equation:

$$
C R R=C R R_{M=7,5} \cdot M S F
$$

where:

$\mathrm{CRR}_{\mathrm{M}=7,5}$ is the cyclic resistance ratio for magnitude 7.5 earthquakes and can be calculated by:

$$
\begin{aligned}
& C R R_{M=7,5}=\frac{1}{34-\left(N_{1}\right)_{60}}+\frac{\left(N_{1}\right)_{60}}{135}+ \\
& \frac{50}{\left[10 .\left(N_{1}\right)_{60}+45\right]^{2}}-\frac{1}{200}
\end{aligned}
$$

MSF is the magnitude scaling factor to be used for magnitudes smaller or larger than 7.5. The MSF is calculated by (Seed and Idriss, 1982):

$$
M S F=\frac{10^{2.24}}{M_{W}^{2.56}}
$$

$\left(\mathrm{N}_{1}\right)_{60}$ is the SPT blow count normalized to an overburden pressure of approximately 100 $\mathrm{kPa}(1 \mathrm{ton} / \mathrm{sqft})$ and a hammer energy ratio or hammer efficiency of $60 \%$ and can be calculated by the formula:

$$
\left(N_{1}\right)_{60}=N_{m} \cdot C_{N} \cdot C_{E} \cdot C_{B} \cdot C_{R} \cdot C_{S}
$$

where $\mathrm{N}_{\mathrm{m}}$ is the measured standard penetration resistance; $\mathrm{C}_{\mathrm{N}}$ is the factor to normalize $\mathrm{N}_{\mathrm{m}}$ to a common reference effective overburden stress; $\mathrm{C}_{\mathrm{E}}$ is the correction for hammer energy ratio (ER); $\mathrm{C}_{\mathrm{B}}$ is the correction factor for borehole diameter; $\mathrm{C}_{\mathrm{R}}$ is the correction factor for rod length; and $\mathrm{C}_{\mathrm{S}}$ is the correction for samplers with or without liners. Afterwards, a "fine content" correction was applied to calculated $\left(\mathrm{N}_{1}\right)_{60}$ value in order to obtain an equivalent clean sand value $\left(\mathrm{N}_{1}\right)_{60 \mathrm{cs}}$ given by the equations proposed by Youd et al. (2001).

\subsection{Determination of the cyclic stress ratio (CSR)}

Seed and Idriss (1971) formulated the following equation for calculation of the cyclic stress ratio: 


$$
\operatorname{CSR}=\frac{\tau_{c y c}}{\sigma_{v 0}^{\prime}}=0.65 r_{d}\left(\frac{\sigma_{v 0}}{\sigma_{v 0}^{\prime}}\right)\left(\frac{a_{\max }}{g}\right)
$$

where: $a_{\max }$ is the peak horizontal acceleration at the ground surface generated by the earthquake, $\mathrm{g}$ is the acceleration of gravity, $\sigma_{v_{0}}$ and $\sigma_{v_{0}}^{\prime}$ are total and effective vertical overburden stresses, respectively; and $r_{d}$ is the stress reduction coefficient.

Quantities $\sigma_{\mathrm{v} 0}, \sigma$,v0 are calculated by the following equations (Kayen et al., 1992):

where:

$$
\begin{gathered}
\sigma_{v 0}=\gamma_{d} z_{w}+\gamma_{s a t}\left(z-z_{w}\right) \\
\sigma_{v 0}^{\prime}=\gamma_{d} z_{w}+\gamma_{b}\left(z-z_{w}\right)
\end{gathered}
$$

$\gamma_{d^{-}}$dryunit weight of soil, in $\mathrm{kN} / \mathrm{m}^{3}$;

$\gamma_{\text {sat }^{-}}$saturated unit weight of soil, in $\mathrm{kN} / \mathrm{m}^{3}$;

$\gamma_{b}$ - floating unit weight of soil, in $\mathrm{kN} / \mathrm{m}^{3}$;

z- calculation depth of $\sigma_{v 0}, \sigma_{v 0}^{\prime}$, in m;

$z_{w}$ - grown water depth, in $\mathrm{m}$.

The coefficient $r_{d}$ accounts for flexibility of the soil profile and can be determined as follows (Liao and Whitman (1986):

$r_{d}=\int 1-0.00765 \times z$ with $z \leq 9.15 m$

$r_{a}=1.174-0.0267 \times z$ with $9.15 m<z \leq 23 m$

\subsection{Determination of the factor of safety against liquefaction (FS) for each sediment layer}

The factor of safety against liquefaction (FS) is determined for each sediment layer by the following formula:

$$
F S=\frac{C R R}{C S R}
$$

where CRR and CSR are the cyclic stress ratio and the cyclic resistance ratio of the soil layer obtained from the two previous steps of the procedure.

\subsection{Calculation of the Liquefaction Poten- tial Index (LPI)}

The Liquefaction Potential Index is calculated for each soil column at a boring point by the following equation (Iwazaki et al., 1982):

$$
L P I=\int_{0}^{z} F(z) w(z) d z
$$

where $\mathrm{z}$ is the depth below the ground surface in meters (usually taken from 0 to $20 \mathrm{~m}$ ) and is calculated as $\mathrm{w}(\mathrm{z})=10-0.5 \mathrm{z} ; \mathrm{F}(\mathrm{z})$ is a function of the factor of safety against liquefaction, $\mathrm{FS}$, where $\mathrm{F}(\mathrm{z})=1-\mathrm{FS}$ when $F S \leq 1$, and $\mathrm{F}(\mathrm{z})=0$ when $\mathrm{FS}>1$.

In addition to the simplified procedure described above, in this study the empirical relationship between LPI and probability of liquefaction proposed by Papathanassiou (2008) was used for mapping of liquefaction hazard for the study area:

$$
P_{G}=\frac{1}{\left(1+e^{3.092-0.218 L P I}\right)}
$$

\section{Seismotectonic characteristics of the Hanoi region}

\subsection{Active faults}

The role of controlling the tectonic regime and seismic activity of the North Vietnam in general and the Hanoi region, in particular, the Red River Fault Zone (below referred to as RRFZ), also known as Ailao Shan-Red River shear zone. Originated from Tibet, China, the RRFZ spreads over 1000 kilometers along the NW-SE direction, crossing over the North Vietnam's territory until it reaches to the Bac Bo gulf (Figure 1). The RRFZ is considered to be a boundary between the South China and the Indochina blocks. In the territory of Vietnam, the RRFZ is characterized by the Elephant Range (also known as Day Nui Con Voi) metamorphic massive, which is bounded by the Red River fault to the SW and the Chay river fault to the NE.

Results of detail geomorphologic investigation show that the Red River fault consists of two branches stretching along the two banks of the Red River. According to the geophysical data, the Red River fault is a deepseated fault that crosses through the Moho, with the average depth of more than $30 \mathrm{~km}$ (Bui Cong Que, 1983). Right lateral strike-slip offsets of these faults are determined by 
analyzing tributaries, stream channels, Quaternary alluvial fans and river valleys on Landsat and SPOT images, on detailed topographical maps, and by field observations.
Geomorphology and topographical offsets suggest that these strike-slip movements are combined with normal slip (PhanTrong Trinh et al., 2012).

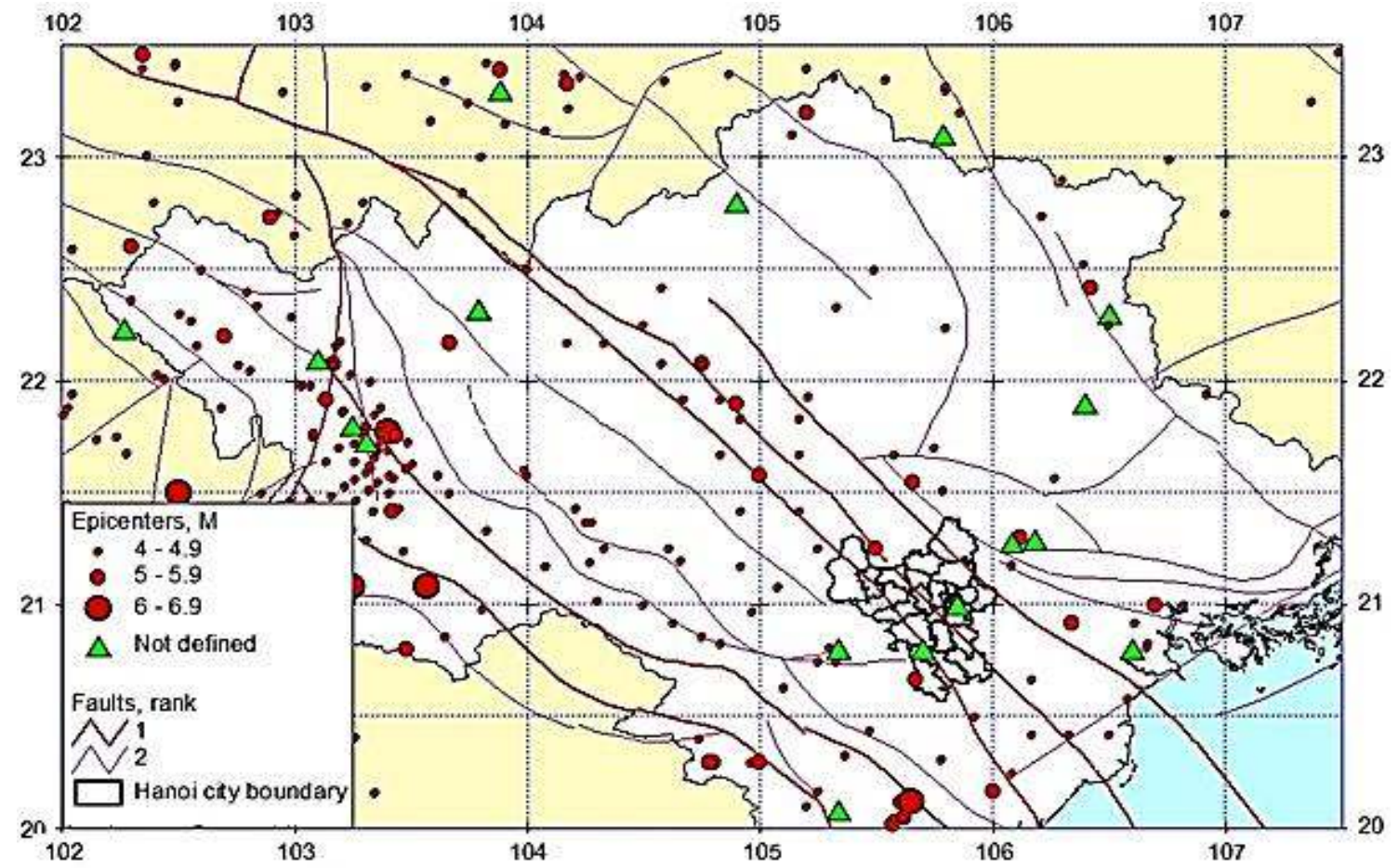

Figure 1. Seismotectonic map of the North Vietnam. The earthquake catalog used includes historical and instrumental data updated until 2015

The Chay River fault is also identified as a deep-seated fault, stretching along the NE boundary of the Elephant Range metamorphic massive from Lao Cai to Viet Tri. The fault is clearly seen on the satellite Landsat and SPOT images. By analyzing the deviation across the fault of the stream network, Phan Trong Trinh et al. (2012) suggested that the offset of the right lateral displacement of the stream is 150 $700 \mathrm{~m}$; average offset is $150 \mathrm{~m}$. According to observed seismicity, the seismic active layer along the fault is determined within the depth from 20 to $25 \mathrm{~km}$ (Nguyen Dinh Xuyen 1987).

Using the average length of offset channels and a minimum rate of $100-150 \mathrm{~mm} / \mathrm{yr}$ for river propagation, Phan Trong Trinh et al., 2012 estimated the horizontal slip rates of
$2.9 \pm 1.7 \mathrm{~mm} / \mathrm{yr}$ for the Chay river fault, $2.3 \pm 1.5 \mathrm{~mm} / \mathrm{yr}$ for the NE branch and $2.1 \pm 1.5$ $\mathrm{mm} / \mathrm{yr}$. for the SW branch of the Red River fault.

Located in the NE and almost parallel to the RRFZ is the Lo river fault. According to the geologic data, the fault appeared in Early Paleozoic. The fault is clearly seen on the satellite images, DEM maps from Tuyen Quang to Tam Dao and inferred to be continued until it reaches to the coast of the East Vietnam Sea if not be overshadowed by the sediments of the North Vietnam's delta. At Tuyen Quang, the fault is mainly identified as a right strikeslip, but along the SW side of Tam Dao mountain, it appears as a normal fault, dipping 70-800 to the SW direction. Some authors ar- 
gue that the Lo river fault is a part of the RRFZ (Phan Trong Trinh 2004).

Judging by size and role of controlling the regional tectonic activity, the Red River fault, the Chay River fault, and the Lo river fault are considered as the first rank of the seismically active faults which are capable of producing earthquakes in the territory of North Vietnam. These three active faults are parallel and crossing the Hanoi's territory in the NW-SE direction.

Another active fault that crosses nearby Hanoi city is the Dong Trieu - Uong Bi fault, with the average depth of $30 \mathrm{~km}$ and dipping 60-800 to the NE direction. In the present time, the Dong Trieu - Uong Bi fault is assessed as left-lateral strike-slip, which is differing from the movement mechanism of the RRFZ. Regardless the fact that the Dong Trieu - Uong Bi fault belongs to a group of second-ranked active faults, its seismic impact to the Hanoi city has always been considered (Nguyen Hong Phuong et al., 2002; 2006).

\subsection{Seismic activity}

While the large earthquakes were not recorded in the Vietnamese part of the RRFZ, the events with medium magnitude occurred quite frequently (Figure 1). During less than a century, from 1910 to 2005,33 earthquakes with magnitude exceeding 4.0 have been instrumentally recorded within the zone. In addition, it is worth to mention the historical events, which might have occurred during the years $1277,1278,1285$ and can be traced in the ancient annals. As described in literature, the first event "had caused a crack of 7 zhangs length ( 24 meters) in the surface", while the second event was "a swam of three strong shakings during a day", and the third event "had made the gravestone in Bao Thien temple broken in two, and caused landslide in the Cao Son mountain" (Nguyen Dinh Xuyen, 2004). As evaluated by seismologists, the shakings of these historical earthquakes are comparable with intensity 7 or $7-8$ on the Macroseismic scale.

Among the earthquakes observed in the RRFZ, the largest events were concentrated along the Chay River fault. There were 3 events with magnitudes exceeding 5.0 instrumentally recorded along this fault, of which the epicenter of Yen Lac earthquake $(\mathrm{M}=5.3$, occurred in 1958) is located within the territory of Hanoi city. The two other events have occurred in the territory of Yen Bai province, namely the Luc Yen earthquake $(\mathrm{M}=5.3$, recorded in 1954) and the Yen Binh earthquake $(\mathrm{M}=5.2$, recorded in 1961). It is also worth to note that three historical events described above (occurred right in the ancient city of Hanoi during 1277, 1278 and 1285) are assumed to be caused by the Chay River fault.

Seismic activity along the Red River fault is quite similar to that of the Chay River fault, but wicker in terms of frequency and magnitude. Three earthquakes with magnitudes $\mathrm{M}=5.0$ were instrumentally recorded along the Vietnamese part of this fault. The nearest to Hanoi event is the Kim Boi earthquake $(M=5.0$, occurred in 1934). The two others events occurred further from Hanoi was the Yen Mo earthquake in Ninh Binh province $(M=5.0$, occurred in 1914) and the Ha Hoa earthquake in Phu Tho province $(\mathrm{M}=5.0$, occurred in 1947).

Outside of the RRFZ, the Dong Trieu Uong Bi fault, although is evaluated as the second-ranked active fault, had provoked a serial of strong earthquakes including the BacGiang earthquake $(\mathrm{M}=5.6$, occurred in 1961), the Mao Khe earthquake ( $M=5.1$, occurred in 1903), and the Dai Tu earthquake $(\mathrm{M}=5.0$, occurred in 1967). The seismicity along the Lo River fault is weaker, where earthquakes of magnitudes not exceeding 4.8 have been recorded with sparse frequency.

\subsection{The scenario earthquakes}

Seismically, the Hanoi region is mostly affected by the Red River Fault Zone, which 
consists of three deep-seated seismically active faults, namely Red River, Chay River and Lo River faults. Coupled with the Dong TrieuUong Bi faults in the northeast, these three active faults are crossing the boundary of Hanoi city as shown in Figure 2. To evaluate the liquefaction hazard for the study area, the seis- mic inputs as $a_{\max }$ and $M_{w}$ were determined from scenario earthquakes. A scenario earthquake is an event, most likely to have to occur in the future, and with predefined parameters. In another word, scenario earthquake is a simulation of an event in the past for predicting the effects of a future event.

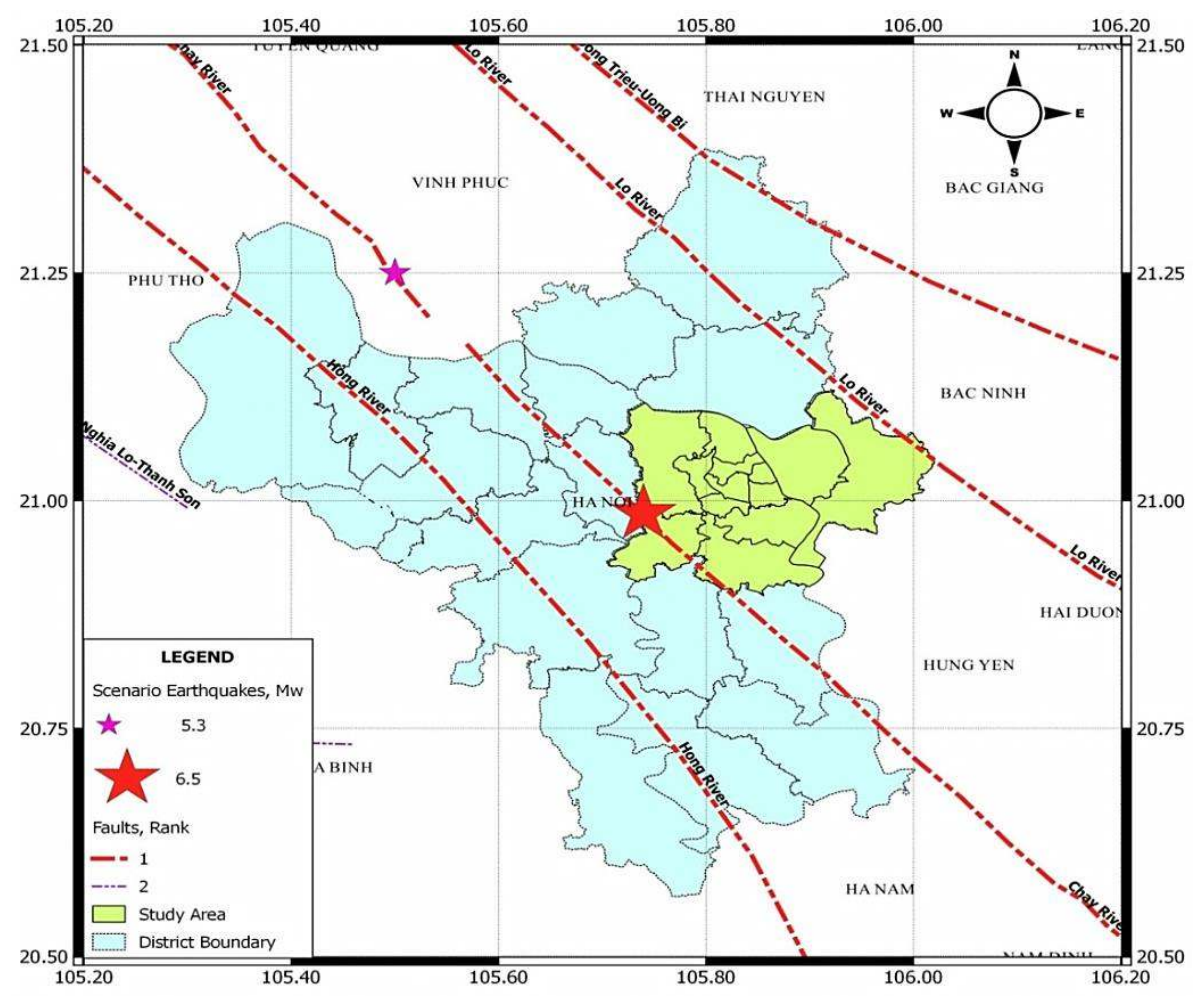

Figure 2. Distribution of active faults in Hanoi region and epicenters of scenario earthquakes

The seismic fault source model of Vietnam was used for the creation of scenario earthquakes (Nguyen Hong Phuong, 2007). The creation of scenario earthquakes in the Hanoi city region is based on the following assumptions:

- Earthquake originated on one of the active tectonic faults which crosses through or nearby the site (urban area).

- Except for the epicenter's coordinates, the other parameters of the scenario earthquake are determined on the basis of geomet- ric and geodynamic characteristics of the fault rupture source following the rules of the seismic fault source model.

In this paper, two scenario earthquakes originated on the Chay River fault were selected. Their parameters are listed in Table 1. The parameters of the first scenario earthquake coincide with a past event occurred in Hanoi in 1958, while the magnitude of the second scenario earthquake $(\mathrm{M}=6.5)$ was chosen in accordance with the maximum earthquake magnitude predicted for Hanoi region 
Bui Thi Nhung, et al./Vietnam Journal of Earth Sciences 40 (2018)

and for the Chay River fault as well (Nguyen Nguyen Hong Phuong, 2003; 2006; Phan Dinh Xuyen, 1996; Nguyen Ngoc Thuy, 2004; Trong Trinh, 2012).

Table 1. Parameters of the scenario earthquakes used in this study

\begin{tabular}{|c|c|c|c|c|c|c|}
\hline \multirow{2}{*}{$\mathrm{N}^{\mathrm{o}}$} & \multirow{2}{*}{ Scenario code } & \multirow{2}{*}{ Source fault } & \multirow{2}{*}{$\mathrm{M}_{\mathrm{w}}$} & \multicolumn{2}{|c|}{ Epicenter's coordinates } & \multirow{2}{*}{ Focal depth, $(\mathrm{km})$} \\
\hline & & & & Longitude (deg) & Latitude (deg) & \\
\hline 1 & DD HN SC5.3 & Chay River & 5.3 & 105.5 & 21.25 & 17 \\
\hline 2 & DD HN SC6.5 & Chay River & 6.5 & 105.73959 & 20.98574 & 17 \\
\hline
\end{tabular}

The shaking maps caused by two scenario earthquakes are illustrated in Figure $3 \mathrm{a}$ and $3 \mathrm{~b}$, showing the distribution of peak ground acceleration (PGA), in g. As can be seen from these maps, the shaking attenuation is clearly reflected different locations of earthquake epicenters.

By combining the shake maps with the sitemap, the peak horizontal acceleration at the ground surface can be determined at every borehole point by the following formula:

$$
\mathrm{a}_{\max }=\mathrm{F}_{\mathrm{a}} \mathrm{PGA}
$$

Where $F_{a}$ is the site amplification factor, $F_{a}=1,6$ for site class $D, F_{a}=2.5$ for site classes $\mathrm{E}$ and $\mathrm{F}$ (Fema 1999). Figures 4a and 4b illustrate distribution of $a_{\max }$ in the study area due to scenario earthquakes.

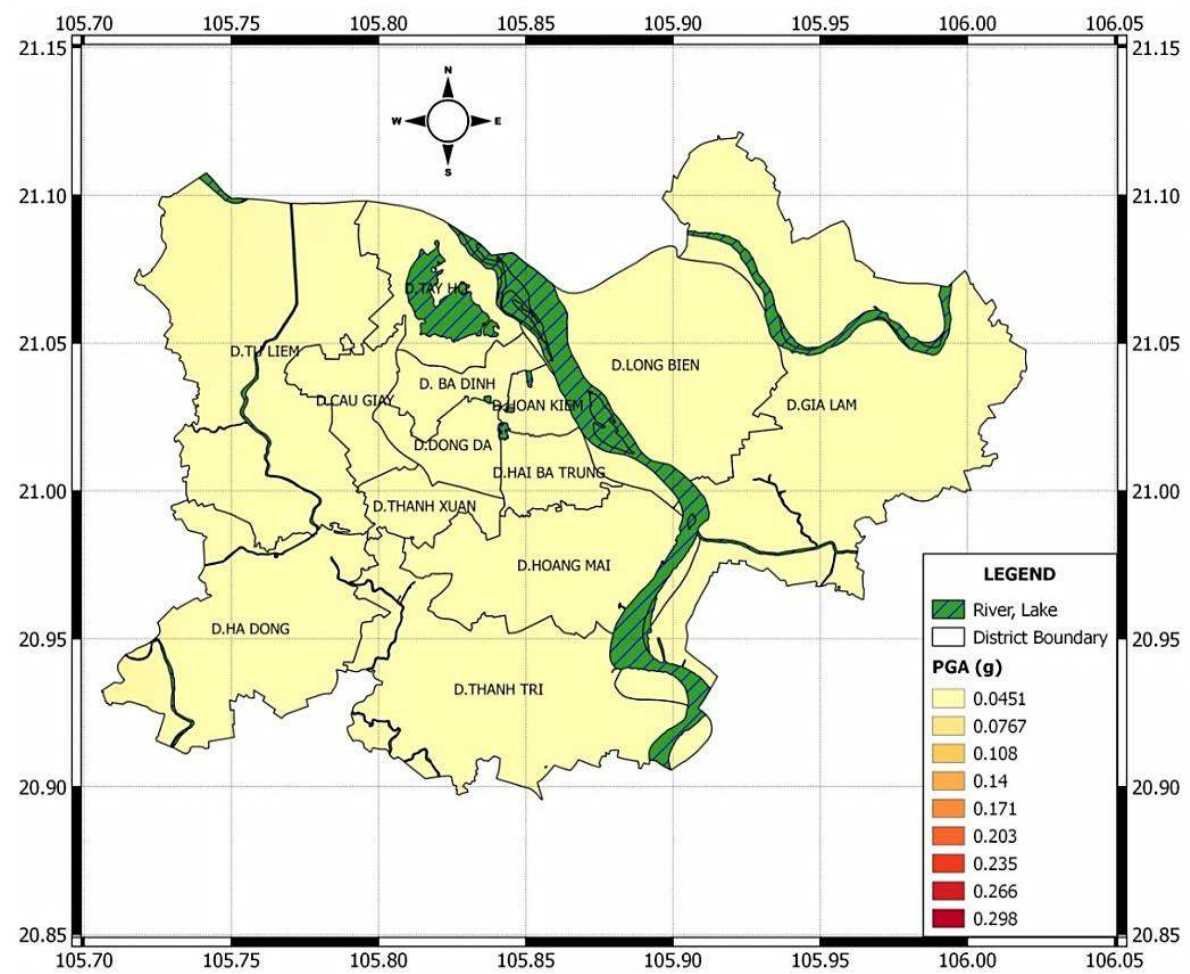

Figure 3a. Distribution of PGA in the study area due to the DD_HN_SC5.3 scenario earthquake (M=5.3) 
Vietnam Journal of Earth Sciences, 40(1), 78-96

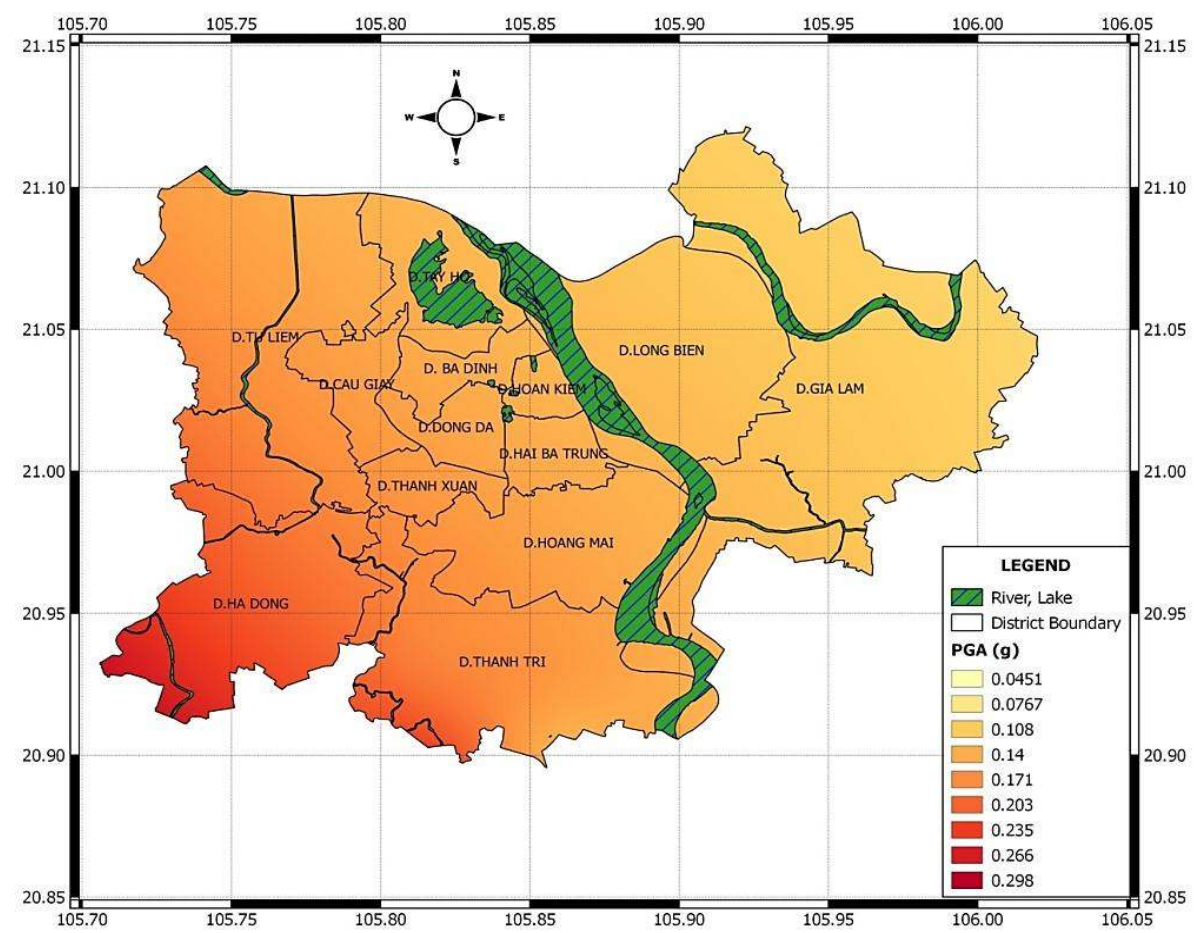

Figure 3b. Distribution of PGA in the study area due to the DD_HN_SC6.5 scenario earthquake (M=6.5)

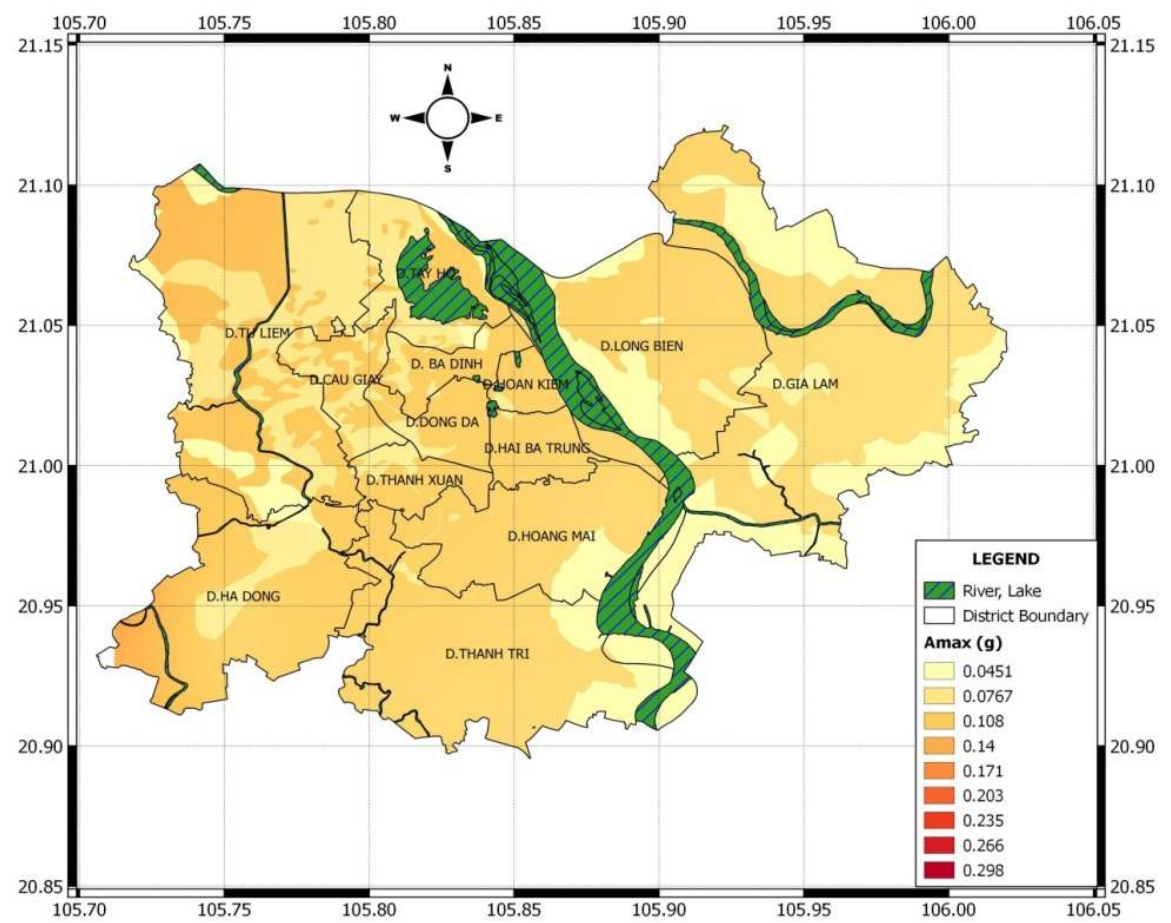

Figure 4a. Distribution of the peak horizontal acceleration at the ground surface generated by the DD_HN_SC5.3 scenario earthquake $(\mathrm{M}=5.3)$ 


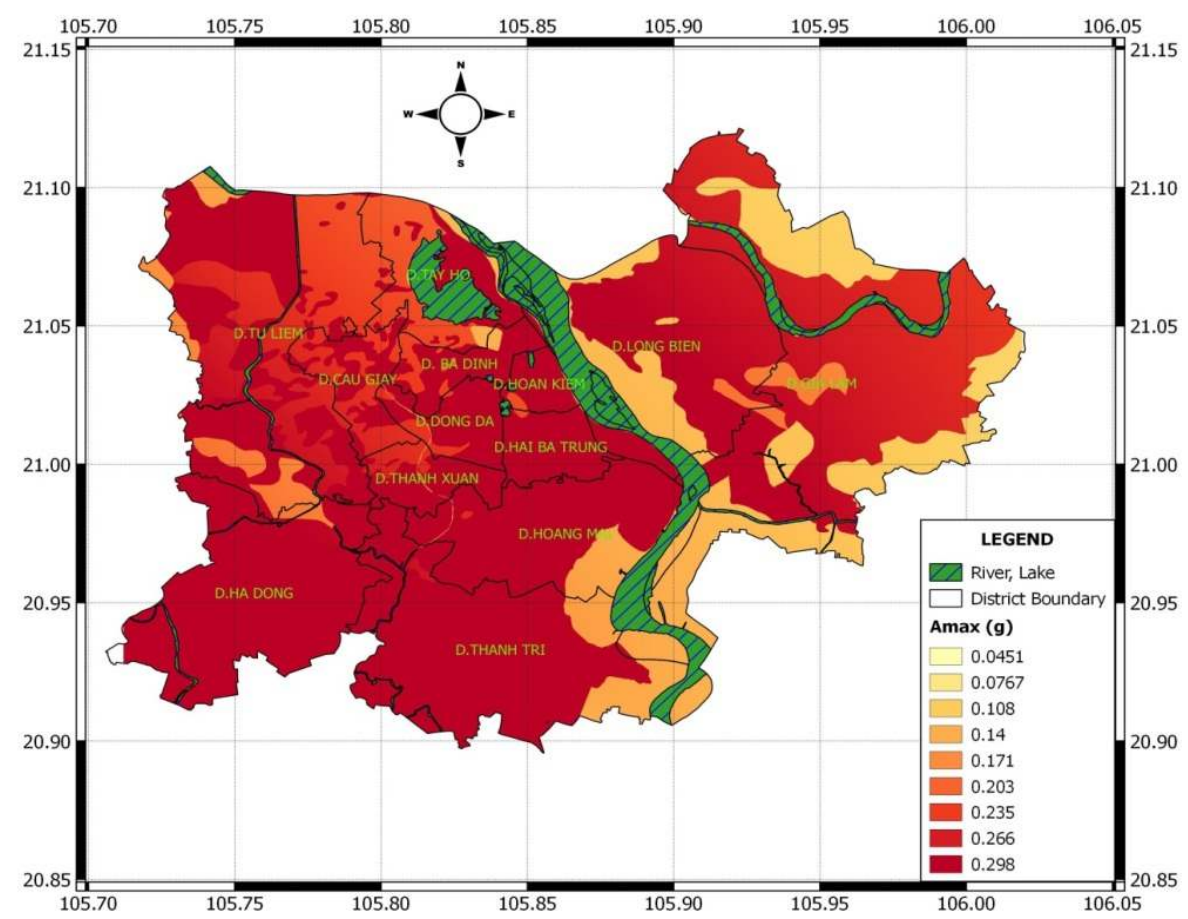

Figure 4b. Distribution of the peak horizontal acceleration at the ground surface generated by the DD_HN_SC6.5 scenario earthquake $(\mathrm{M}=6.5)$

\section{Subsoil characteristics}

For evaluating the liquefaction potential for the study area, beside the seismic inputs as $a_{\max }$ and $\mathrm{M}_{\mathrm{w}}$, a dataset containing 120 borehole logs collected from several research and construction projects was also used (Nguyen Huy Phuong 2004; 2010). Location of the boreholes used in this study is shown in Figure 5. An example of a borehole log used in this study is shown in Figure 6. The borehole logs data contains all necessary information on geomechanical characteristics of each layer in everyborehole as shown in an example in Table 2. Coupled with such geomechanical information as the fine contents, specific gravity, dry density and the porosity of the subsoil layers, such other parameters as the $\mathrm{N}$ values of SPT at different depth $\mathrm{Z}$, the groundwater level $\mathrm{Z}(\mathrm{w})$ at each borehole was also used for liquefaction potential evaluation. In the case where the information on the groundwater depth is lacking, a default value of $2 \mathrm{~m}$ was assigned to conform with the average value of the qh static groundwater level, widely is tributed in the Hanoi region (Vu Thanh Tam et al., 2014).

\section{Evaluation of earthquake-induced lique- faction potential for urban areas of Hanoi city}

The factor of safety against liquefaction was calculated for each sediment column at 120 borehole points following the simplified procedure described above. An example of the FS calculation results at a borehole is shown in Table 3. Results obtained at some borehole points are shown in Figure 7. 
Vietnam Journal of Earth Sciences, 40(1), 78-96

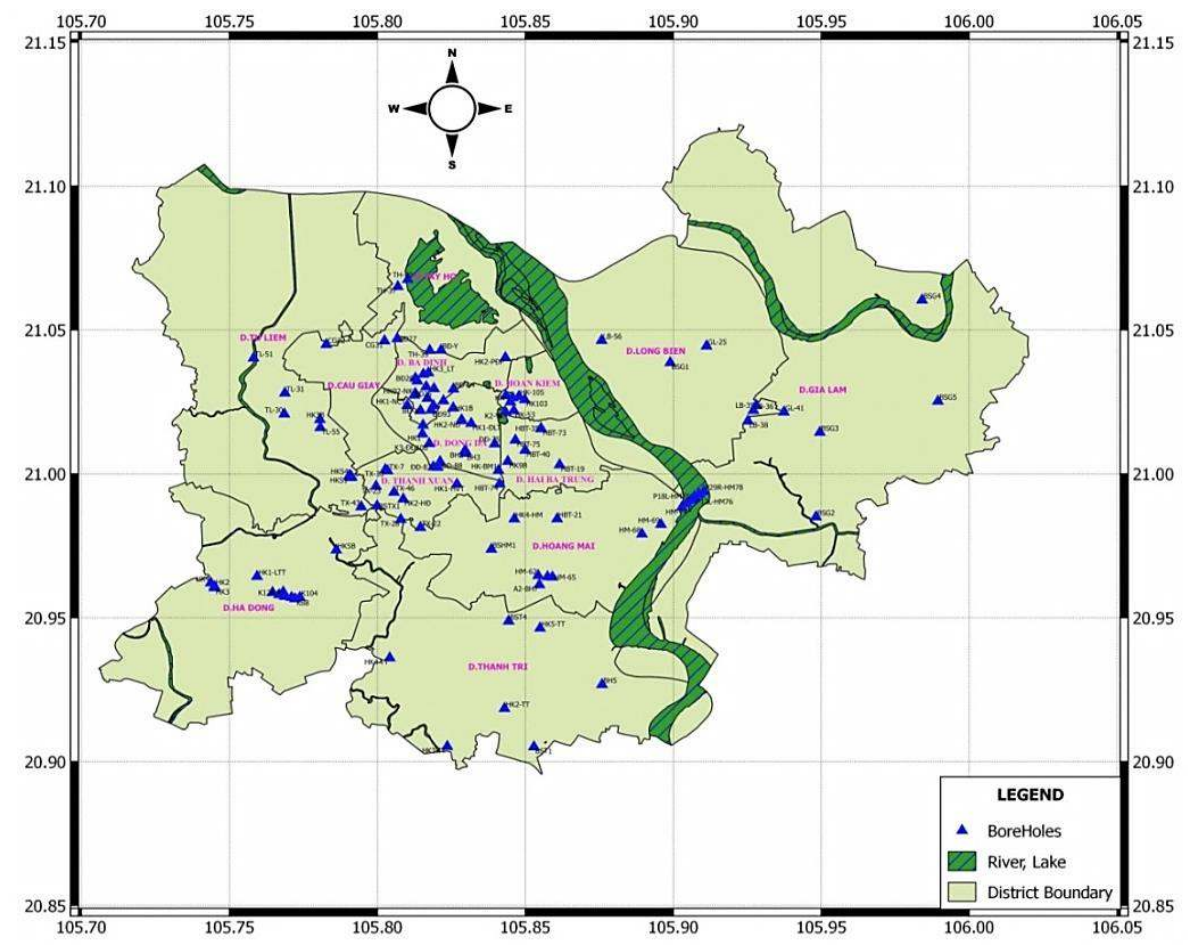

Figure 5. Distribution of boreholes with SPT in the study area

Table 2. An example of geomechanic characteristics of a subsoil layer extracted from a borehole log, where the information on fine content, specific gravity $(\rho s)$, dry density $\left(\rho_{\mathrm{d}}\right)$ and void ratio (e) were used in analysis.

Layer 2: Mud- lake, pond bed. Particle size analysis (sand $(2-0.05) 42.8 \%$, silt $(0.05-0.005) 29.9 \%$, clay $(<0.005)$ $27.3 \%)$.

\begin{tabular}{|c|c|c|c|c|c|c|}
\hline \multirow{2}{*}{$\mathrm{N}^{0}$} & \multirow{2}{*}{ Property } & \multirow{2}{*}{ Unit } & \multirow{2}{*}{ Symbol } & \multicolumn{3}{|c|}{ Value } \\
\hline & & & & $A_{t c}$ & $\sigma$ & $\mathrm{V}$ \\
\hline 1 & Moisture contents & $\%$ & $\mathrm{~W}$ & 52.5 & 19.54 & 0.37 \\
\hline 2 & Natural density & $\mathrm{g} / \mathrm{cm}^{3}$ & $\rho$ & 1.67 & 0.15 & 0.09 \\
\hline 3 & Dry density & $\mathrm{g} / \mathrm{cm}^{3}$ & $\rho_{\mathrm{d}}$ & 1.10 & - & - \\
\hline 4 & Specific gravity & $\mathrm{g} / \mathrm{cm}^{3}$ & $\rho s$ & 2.62 & 0.10 & 0.04 \\
\hline 5 & Void ratio & - & $\mathrm{e}$ & 1.383 & - & - \\
\hline 6 & Porosity & $\%$ & $\mathrm{n}$ & 58 & - & - \\
\hline 7 & Degree of saturation & $\%$ & G & 99.2 & - & - \\
\hline 8 & Liquid limit & $\%$ & Wch & 50.5 & 16.62 & 0.33 \\
\hline 9 & Plastic limit & $\%$ & $\mathrm{Wd}$ & 34.8 & 14.53 & 0.42 \\
\hline 10 & Plasticity index & $\%$ & IP & 15.7 & - & - \\
\hline 11 & Consistency & - & Is & 1.13 & - & - \\
\hline 12 & Internal friction angle & $\operatorname{deg}$ & $\varphi$ & $5^{0} 44^{\prime}$ & - & - \\
\hline 13 & Cohesion & $\mathrm{KG} / \mathrm{cm}^{2}$ & $\mathrm{C}$ & 0.080 & 0.05 & 0.59 \\
\hline 14 & Compression ratio & $\mathrm{Cm}^{2} / \mathrm{KG}$ & $a_{1-2}$ & 0.093 & 0.05 & 0.50 \\
\hline 15 & Deformation module & $\mathrm{KG} / \mathrm{cm}^{2}$ & $\mathrm{E}_{0}$ & 15.8 & - & - \\
\hline 16 & Resistance capacity & $\mathrm{KG} / \mathrm{cm}^{2}$ & $\mathrm{R}_{0}$ & 0.61 & - & - \\
\hline 17 & SPT value & Hammer & $\mathrm{N}_{30}$ & 2 & 0.98 & 0.40 \\
\hline 18 & Total number of samples & Sample & $\mathrm{n}$ & & 56 & \\
\hline
\end{tabular}


Bui Thi Nhung, et al./Vietnam Journal of Earth Sciences 40 (2018)

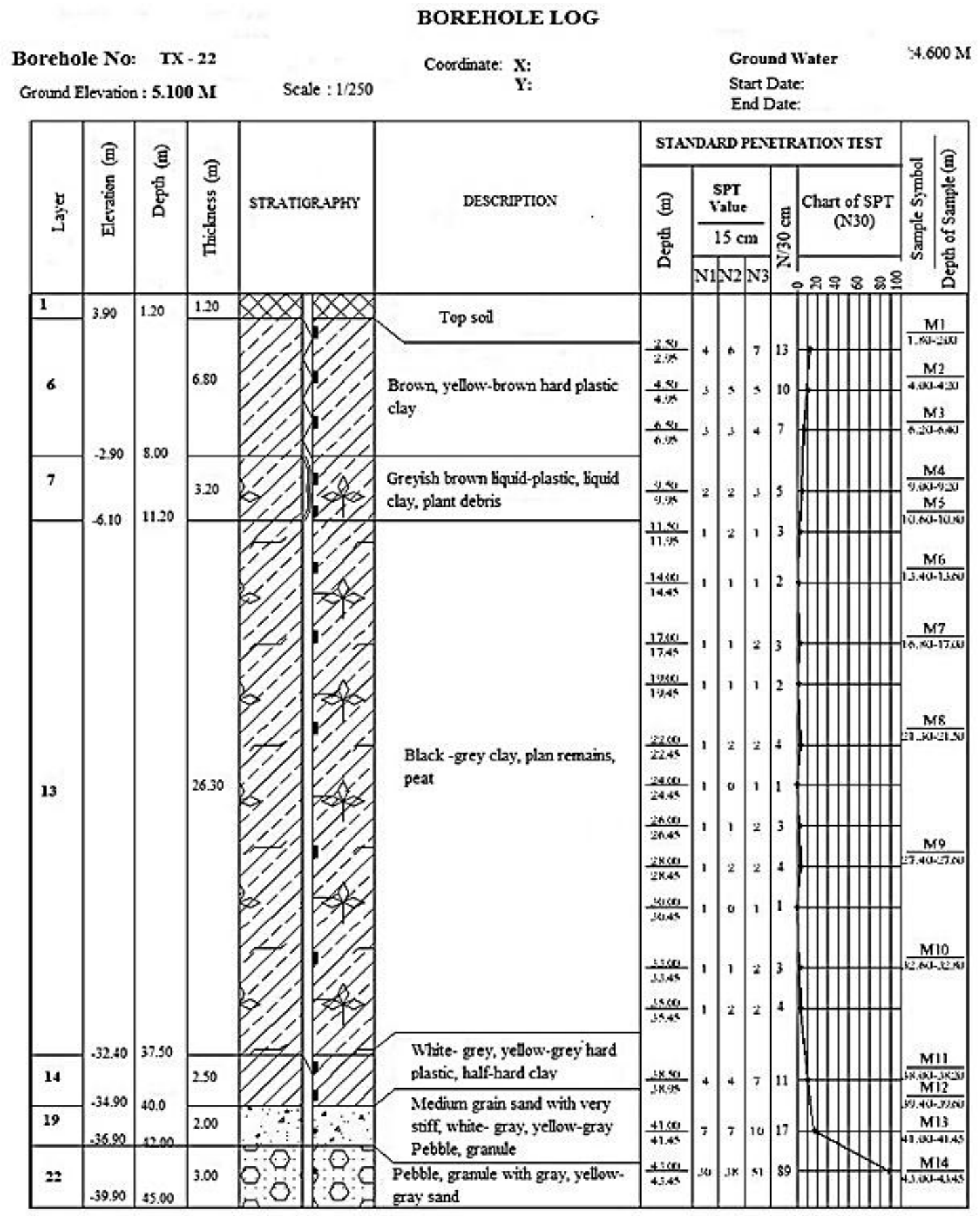

Figure 6. Illustration of the TX-22 borehole log with information on N(SPT), ground water level and layers contents to be used for calculation 
Vietnam Journal of Earth Sciences, 40(1), 78-96

Table 3. An example of the results of FS calculation for sediment column at the TX-22 borehole point $\left(\mathrm{a}_{\max }=0.287909 \mathrm{~g}, \mathrm{M}_{\mathrm{w}}=6.5, \mathrm{w}(\mathrm{z})=4.6 \mathrm{~m}\right)$

\begin{tabular}{|c|c|c|c|c|c|c|c|c|c|c|c|c|c|c|c|c|c|c|}
\hline ayer & $\mathrm{FC}(\%)$ & $a$ & $\beta$ & $\begin{array}{c}\text { Specific } \\
\text { gravity } \rho_{\mathrm{s}} \\
\left(\mathrm{g} / \mathrm{cm}^{\wedge} 3\right) \\
\end{array}$ & $\begin{array}{c}\text { Dry } \\
\text { density } \rho_{\mathrm{d}} \\
\left(\mathrm{g} / \mathrm{cm}^{\wedge} 3\right) \\
\end{array}$ & $\begin{array}{l}\text { Void } \\
\text { ratio e }\end{array}$ & $Z(m)$ & $\begin{array}{l}\text { SPT } \\
\text { N30 }\end{array}$ & $\sigma_{0}$ & $\sigma_{0}$ & $\begin{array}{c}r_{d} \\
(\mathrm{~m})\end{array}$ & CSR & $\mathrm{CN}$ & $\left(N_{1}\right)_{60}$ & $\left(N_{1}\right)_{60 c s}$ & c & RRm & FS \\
\hline 6 & 30.7 & 75 & 1 & 2.7 & 1.46 & 0.847 & 2. & 11 & 5 & & 0.977 & & & & & & 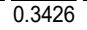 & 1 \\
\hline 6 & 3 & & & 7 & & & & 10 & & & & & & & & & & 656 \\
\hline 6 & & & & & & & & & & & & & & & & & & \\
\hline 7 & 7.7 & & & . & 1.22 & & 9.5 & 5 & & & 0.908 & & & & & & & 0.7 \\
\hline 13 & 29.4 & 4.6654 & 1.1494 & 2.5 & 1.04 & 1.483 & 11.95 & 3 & 166.04 & 92.540 & 0.854 & & & 3.1248 & & & & 0.6046 \\
\hline 13 & 29.4 & & & & 1.04 & 1.483 & 14.45 & 2 & & 108 & 0.788 & & & & & & & 0.5442 \\
\hline 15 & & & & & & & & & & & & & & & & & 8 & \\
\hline 13 & & & & & & & & 2 & & & & & & & & & & \\
\hline 13 & 29.4 & 4.6654 & 1.1494 & 2.59 & 1.04 & 1.483 & 22.45 & 4 & 336.19 & 157.69 & 0.574 & 0.2292 & 0.7963 & 3.1916 & 8.3339 & 0.0987 & 0.1747 & 0.7622 \\
\hline
\end{tabular}

As can be seen from Figure7, the FS values calculated from the second scenario earthquake (DD_HN_SC6.5) are always smaller than those calculated from the first one (DD_HN_SC5.3). It means that, for a point with certain soil conditions, the stronger impact from earthquake will cause higher liquefaction potential. As shown by the data analy- sis, in the study area exit the boreholes with the soil columns containing at the same time liquefiable (FS $>1$ ) as well as non-liquefiable $(\mathrm{FS}<1)$ layers. This fact can be used in practice for choosing a construction site, where the sites with a thin non-liquefiable layer located on top of a thick liquefiable layer have to be avoided.
FS

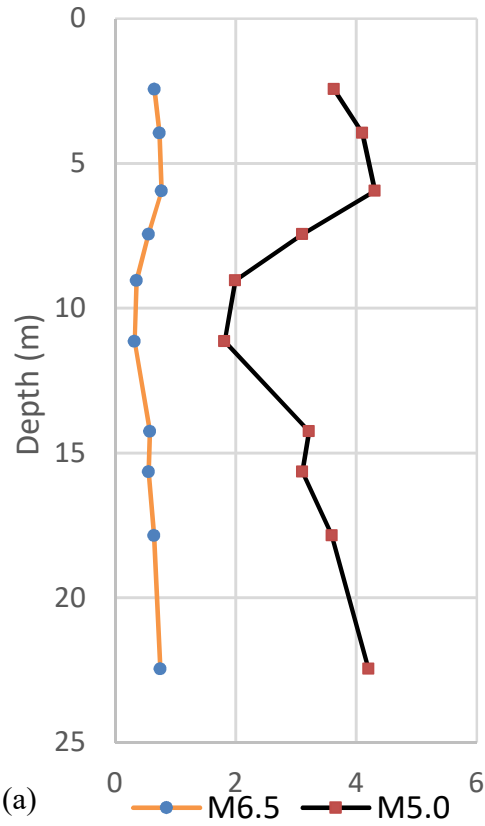

FS

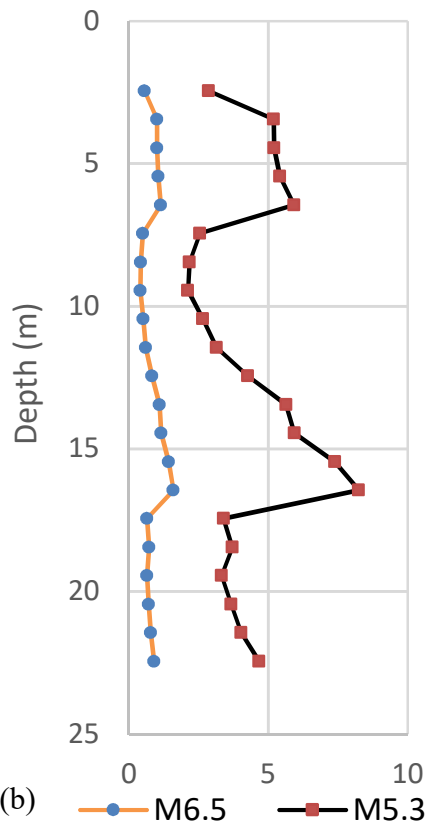

FS

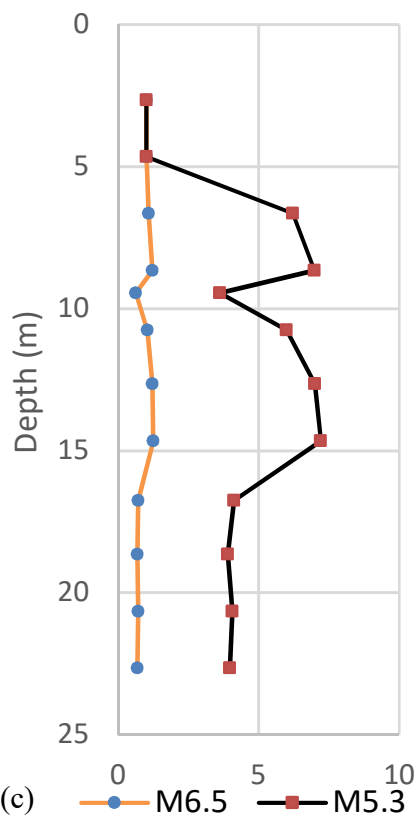

Figure 7. Examples of the factors of safety against liquefaction (FS) calculated from two scenario earthquakes at the boreholes in: (a) Dong Da district (DD-75); (b) Long Bien district (LB-35); and (c) Tu Liem district (TL-31)

The obtained FS values were used in the formula (10) to calculate the Liquefaction Potential Index (LPI) at all 120 borehole sites. Then, formula (11) was used for calculation of liquefaction probability (PG) at all borehole sites. Finally, the liquefaction hazard maps showing the distribution of liquefaction probability in the study area were constructed 
based on the PG values obtained from the two scenario earthquakes using interpolation technique in a GIS environment (Figures 8 and 9). The liquefaction probabilities are compared with the levels of liquefaction potential as shown in Table 4.

From Figures 8, 9 and according to the criteria of liquefaction potential assessment shown in Table 4, one can conclude that for the entire study area, the first scenario earthquake $(\mathrm{Mw}=5.3)$ is not able to cause liquefaction $(\mathrm{PG}<0.1)$, while the second earthquake scenario $(\mathrm{Mw}=6.5)$ is capable of causing liquefaction $(\mathrm{PG}>0.1)$. This is understandable as the shaking caused by the second scenario earthquake in the study area is considerably higher than the shaking caused by the first scenario earthquake.

Table 4. Liquefation potential levels corresponding to the calculated values of earthquake-induced liquefaction probabilities (Li et al., 2006)

\begin{tabular}{cc}
$\mathrm{P}_{\mathrm{G}}$ & Liquefaction potential \\
\hline $0.0-0.1$ & Very low \\
$0.1-0.3$ & Low \\
$0.3-0.7$ & Medium \\
$0.7-0.9$ & High \\
$0.9-1.0$ & Very high \\
\hline
\end{tabular}

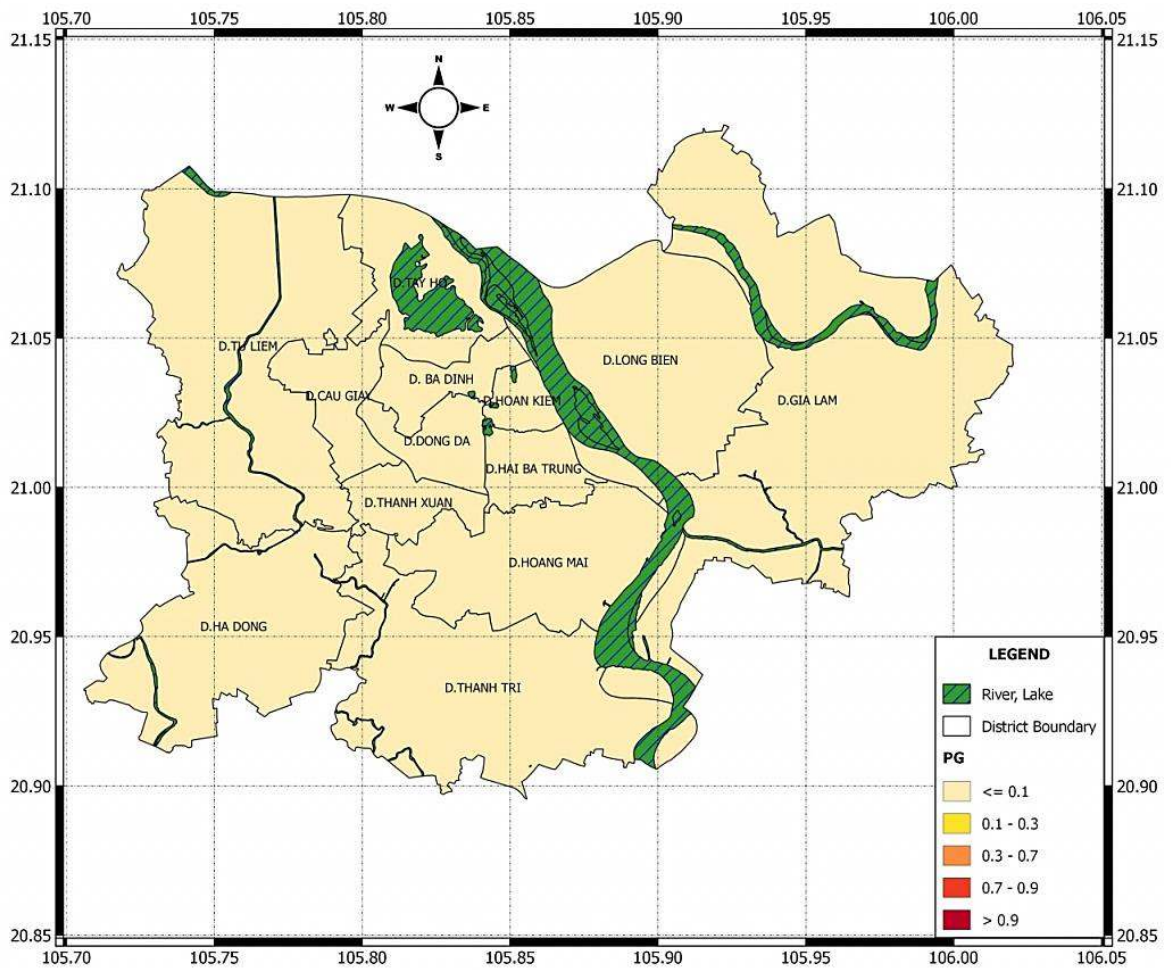

Figure 8. Map showing the probability of liquefaction-induced surface disruption in case of a magnitude 5.3 earthquake and a distribution of $\mathrm{a}_{\max }$ values relatively to the first scenario (DD_HN_SC5.3)

The second scenario earthquake produces different levels of liquefaction potential in the study area. The highest liquefaction probability of $0.7<\mathrm{PG} \leq 0.9$ is distributed in two large areas, where the first one is observed in Thanh
Tri district, eastern part of Ha Dong, a smaller areas of the Thanh Xuan, Tu Liem and Cau Giay districts, while the second area covers Hoan Kiem district, a northern part of Hai Ba Trung district and northwestern part of Long 
Bien district. The zones with medium liquefaction potential $(0.3<\mathrm{PG} \leq 0.7)$ includes majority of the Gia Lam district, eastern parts of the Long Bien and Hoang Mai districts, majority of the Thanh Xuan and Dong Da districts (except for the Dong Da hill where the groundwater level is low), the Cau Giay district, the southern part of $\mathrm{Tu}$ Liem district and the western part of $\mathrm{Ha}$ Dong district.
There are two zones with low liquefaction potential $(0.1<\mathrm{PG} \leq 0.3)$, which located in northern part of the Tu Liem and Tay Ho districts, the small area in Ba Dinh and Dong Da districts and a junction of the Gia Lam, Long Bien, Hai Ba Trung and Hoang Mai districts. The Red River and the West lake areas are left blank on the map due to the limitation of borehole data.

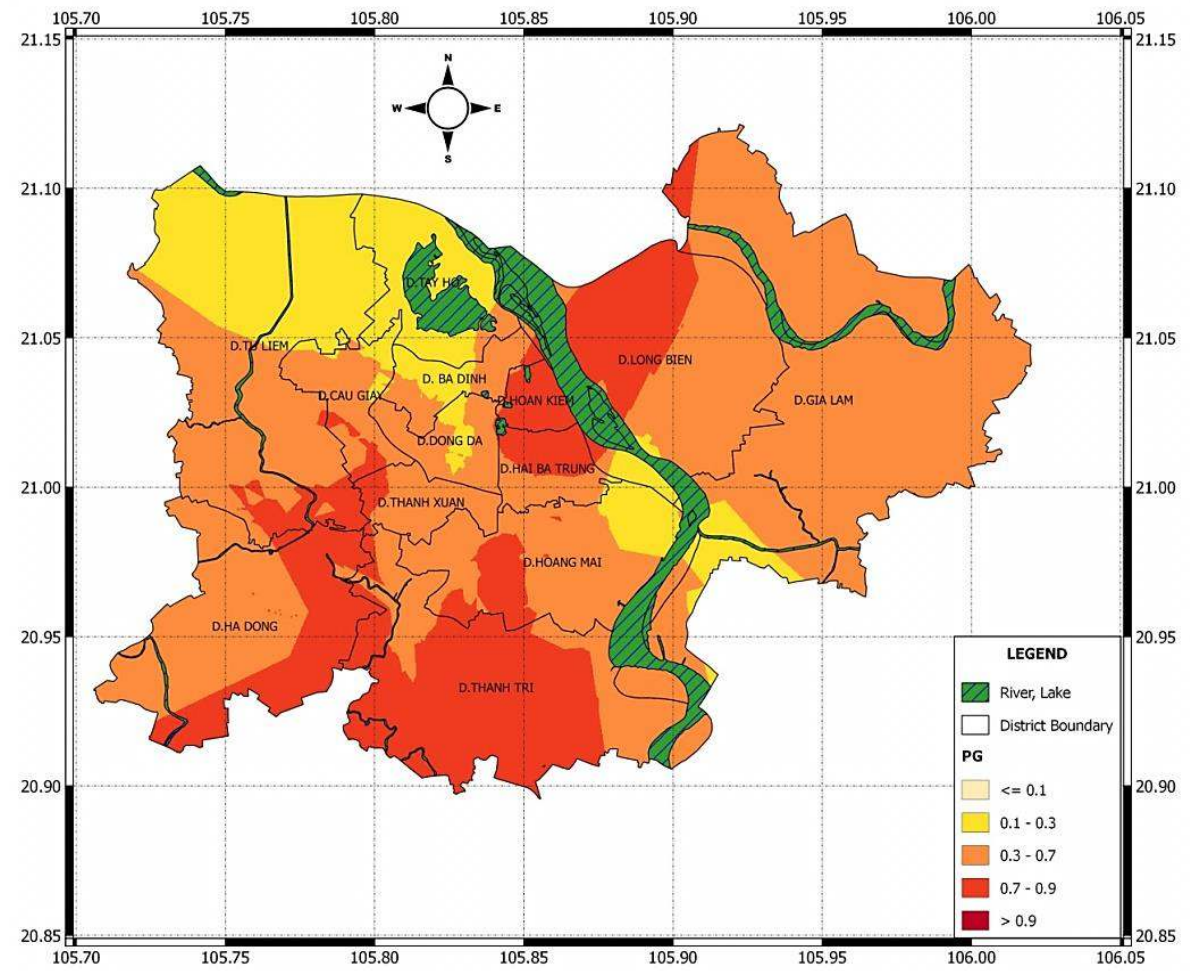

Figure 9. Map showing the probability of liquefaction-induced surface disruption in case of a magnitude 6.5 earthquake and a distribution of $\mathrm{a}_{\max }$ values relatively to the second scenario (DD_HN_SC6.5)

\section{Discussions}

Results obtained from the first scenario $(\mathrm{Mw}=5.3)$ imply the fact that the earthquakes instrumentally observed in the Hanoi region up to now are of moderate magnitude and therefore have the very low probability of producing liquefaction in the downtown area of the city. On the other hand, results of the second scenario $(\mathrm{Mw}=6.5)$ show the fact that an earthquake with magnitude, maximum ex- pected for Hanoi region as assessed by many authors (Nguyen Dinh Xuyen et al., 1996; Nguyen Ngoc Thuy et al., 2004; Nguyen Hong Phuong et al., 2003; 2006) can produce liquefaction throughout the downtown area of Hanoi city.

With consideration of geologic characteristics of various sediment layers at different depths as well as the soil amplification due to seismic shaking, the method applied in this study has given the quantitative results as 
shown by the liquefaction hazard maps. This is considered to be a progress in comparison with the liquefaction susceptibility maps produced in previous works, where only geomorphologic characteristics of the study area were considered without seismic impacts. In comparison with the works done by Nguyen Hong Phuong et al., 2007, 2014) using the methodology modified from HAZUS, the LPI based method of liquefaction evaluation used in this study gave much higher values of liquefaction probability. This fact has been pointed out previously by some authors (Kongar et al., 2016).

The results obtained in this study are also comparable with those done by Nguyen Hong Nam et al. (2016) for some dykes crossing the downtown area of Hanoi city at Dong Ngac, Tu Liem district and at Huu Hong, Hoang Mai district. These authors applied the method proposed by Seed \& Idriss using the PGA values from the Building Code TCXDVN 375-2006, which were determined by the probabilistic method and correspond to the return periods of 2475 and 475 years, respectively. As found by Nguyen Hong Nam et al. (2016), calculation results at three boreholes KC4, KC13, KC15 in Dong Ngac show some liquefiable layers $(\mathrm{FS}<1)$ at the depth of 10.2 $\mathrm{m}$, and calculation results at nine boreholes (from HK1 to HK 9) in Huu Hong show the high potential of liquefaction. This coincides with the results obtained by this study as shown in Figure 9, where values $\mathrm{PG}=0.1 \div 0.3$ obtained at the $\mathrm{Tu}$ Liem district and values $\mathrm{PG}=0.3 \div 0.7$ obtained at the Hoang Mai district.

Characterized by a low level of seismicity, Vietnam is facing difficulty in establishing the empirical models for verifying the results of liquefaction potential for the country (Jaimes et al., 2015; Liu et al., 2016). However, the preliminary results described in this paper show attempts of enhancement of methodology and technique to be used taking into account the World's experience, particularly in terms of seismic input and the uncertainty of soil characteristics.

It should be noted that in this study the uneven distribution of the boreholes data affects the reliability of the mapping results. The high uncertainties are assigning to such areas as the southern part of Ha Dong district, northern parts of Tu Liem and Gia Lam districts due to lacking boreholes data.

\section{Conclusions}

In this study, the LPI-based method was applied to evaluate the earthquake-induced liquefaction potential for the urban area of Hanoi city. Using a dataset of 120 boreholes logs, the "simplified procedure" to evaluate the liquefaction of soil layers in every borehole point. The Liquefaction Potential Index (LPI) was calculated for the whole soil column at all boreholes points and the obtained LPI values were used to assess the liquefaction probability for an urban area of Hanoi city, using the two earthquake scenarios originated on the Chay River fault with magnitudes of 5.3 and 6.5, respectively. Parameters of the first scenario earthquake were selected to coincide with a real event occurred in 1958 , while the second scenario earthquake represents the worst case in terms of shaking that can be expected from this fault source.

The obtained results include the values of the factor of safety against liquefaction (FS) calculated for each layer in 120 borehole soil columns and two liquefaction hazard maps compiled for the urban area of Hanoi city which correspond to two earthquake scenarios.

As shown by the liquefaction hazard map compiled from the first scenario earthquake the entire downtown area of Hanoi city is nonliquefiable. In the meantime, there is a high possibility (with the probability of 0.3 to 0.9 ) that the second scenario earthquake may produce liquefaction in the majority of the downtown area of Hanoi city. Regardless the fact that up to now, the majority of earthquakes 
recorded in Hanoi city and its vicinity are of medium magnitudes, in order to reduce damage and losses caused by liquefaction during future earthquakes, attention and measurements need to be taken for the areas with high and medium liquefaction potentials due to the fast infrastructural development and high population density in the urban area of Hanoi.

\section{References}

Bui Cong Que, 1983. The new results in study of the crustal Structure for the territory of Vietnam. J. Sci. of the Earth, 5(1), 17-24 (in Vietnamese).

Bui Van Duan, Nguyen Cong Thang, Nguyen Van Vuong, Pham Dinh Nguyen, 2013. The magnitude of the largest possible earthquake in the Muong LaBac Yen fault zone. J. Sci. of the Earth, 35, 49-53 (in Vietnamese).

Day R.W., 2002. Geotechnical Earthquake engineering Handbook. McGRaw-Hill New York Chicago San Francisco Lisbon London Madrid Mexico City Milan New Delhi San Juan Seoul Singapore Sydney Toronro. Printed and bound by R.R. Donnelley \& Sons Company.

Dixit J., Dewaikar D.M.and Jangid R.S., 2012. Assesment of liquefaction potential index for Mumbai city. Nat. Hazards Earth Syst. Sci., 12, 2759-2768.

Federal Emergency Management Agency, 1999. NEHRP recommended Provisions for Seismic Regulations for New Buildings, Washington, D. C., Developed by the Building Seismic Safety Council (BSSC) for the Federal Emergency Management Agency (FEMA).

Gillins D.T., 2016. Probabilistic Liquefaction Potential and Lateral Spread Hazard Maps for Utah County, Utah: Collaborative Research with Brigham Young University and Oregon State University. USGS Award Numbers: G14AP00118 \& G14AP00119.Term of Award: 08/01/2014 01/31/2016.

Tran Dinh Hoa and Bui Manh Duy, 2013. Earthquakeinduced liquefaction foudation and the methods of assessment for liquefaction foundation for Kinh Lo barrier Ho Chi Minh City. Journal of Water Resources Science and Technology, 15(4), 21-29.
Ishihara K., 1985. Stability of natural deposits during earthquakes. Proceedings of the 11th International Conference on Soil Mechanics and Foundation Engineering, 1. A.A. Balkema, Rotterdam, The Nertherlands, 321-376.

Iwasaki T., Tatsuoka F., Tokida K. and Yasuda S., 1978. A practicalmethod for assessing soil liquefaction potential based oncase studies at various sites in Japan, In Proceedings of the $2^{\text {nd }}$ International Conference on Microzonation for Safer Construction-Research and Application, San Francisco, Calif., 26 November-1 December. American Society of Civil Engineers, New York, 2, 885-896.

Iwasaki T., Arakawa T. and Tokida K., 1982. Simplified proceduresfor assessing soil liquefaction during earthquakes. InProceedingsof the Conference on Soil Dynamics and EarthquakeEngineering, Southampton, UK, 13-15 July 1982. Balkema,Rotterdam, the Netherlands, 925-939.

Kircher C.A., Whitman R.V., Holmes W.T., 2006. HAZUS earthquake loss estimation methods. Nat Hazards Rev, 7(2), 45-59.

Kongar I., Rossetto T., Giovinazzi S., 2016. Evaluating Simplified Methods for Liquefaction Assessment for Loss Estimation. Nat. Hazards Earth Syst. Sci. Discuss. Doi:10.5194/nhess-2016-281.

Li D.K., Juang C.H. and Andrus R.D., 2006. Liquefaction potentialindex: a critical assessment, Journal of GeoEngineering,Taiwan Geotechnical Society, 1(1), 11-24.

Liu F., Li Z., Jiang M., Frattini P. and Crosta G., 2016. Quantitative - induced lateral spead hazard mapping. Engineering Geology, 207, 36-47. Doi: 10.1016/j.enggeo.2016.04.001.

Mustafa Erdik, K. S־ešetyan, M.B. Demirciog $־$ lu, C. Zu"lfikar, U. Hancilar, C. Tu"zu"n, and E. Harmandar., 2014. Rapid Earthquake Loss Assessment After Damaging Earthquakes. Perspectives on European Earthquake Engineering and Seismology, 1, 53-95.

Nguyen Hong Phuong, 2000. An algorithm for seismic risk assessment in Vietnam using a GIS. J. Sci. of the Earth, 22(3), 210-222 (in Vietnamese).

Nguyen Hong Phuong (Project Manager), 2002. Study of seismic risk of Hanoi city. Project code 01C04/09-2001-2. Institute for Marine Geology and Geophysics, VAST. 
Bui Thi Nhung, et al./Vietnam Journal of Earth Sciences 40 (2018)

Nguyen Hong Phuong, 2003. Development of a DSS for seismic risk assessment and Loss reduction using GIS technology. Contributions of the Marine Geophysics and Geology, VII, 62-78 (in Vietnamese).

Nguyen Hong Phuong (Project Manager), 2003. Study of seismic risk of Hanoi city. Final report of the National scientific research Project 01C-04/09-2001-2, Hanoi (in Vietnamese).

Nguyen Hong Phuong (Project Manager), 2007. Application of GIS technology to Development of a model for seismic risk analysis for Hanoi city. Final Report of Research Project, Institute for Marine Geology and Geophysics, VAST.

Nguyen Hong Phuong, 2008. Assessment of earthquake risk for Ho Chi Minh city using GIS and mathematical models. Final Report of Research Project, Institute of Geophysics, VAST (in Vietnamese).

Nguyen Hong Phuong, 2009. Integrated Spatial decision support Systems for Urban Emergencies (ISSUE), Final Report of Vietnam-French Research Project, Hanoi.

Nguyen Huy Phuong (Project Manager), 2010. Study on the phenomenon of coherent action and changes reliability of Hanoi bottom land under the impact of dynamic load in order to improve the geotechnical information system for sustainable development and disaster prevention. Hanoi University of Mining and Geology.

Nguyen Hong Phuong (Project Manager), 2014. Estimation of Site Effects and Assessment of Urban Seismic Risk for Hanoi city. National Scientific Research Project Final report. Institute of Geophysics, VAST.

Papathanassiou G., 2008. LPI-based approach for calibrating theseverity of liquefaction-induced failures and for assessing theprobability of liquefaction surface evidence. Engineering Geology, 96(1-2), 94104. Doi:10.1016/j.enggeo.2007.10.005.

Phan Trong Trinh, Hoang Quang Vinh, Leloup Philippe Hervé, Giuliani G., Vincent Garnier., Tapponnier P., 2004. Cenozoic deformation, thermodynamic evolution, slip mechanism of Red River shear zone and ruby formation. Science and Technics Publishing House, Hanoi, 5-72 (In Vietnamese with English abstract).
Phan Trong Trinh, Ngo Van Liem, Nguyen Van Huong, Hoang Quang Vinh, Bui Van Thom, Bui Thi Thao, Mai Thanh Tan, Nguyen Hoang, 2012. Late Quaternary tectonics and seismotectonics along the Red River fault zone, North Vietnam. Earth-Science Reviews, 114, 224-235.

Phan Trong Trinh, Hoang Quang Vinh, Nguyen Van Huong, Ngo Van Liem, 2013. Active fault segmentation and seismic hazard in Hoa Binh reservoir, Vietnam. Cent. Eur. J. Geosci., 5(2), 223-235.

Jaimes M.A, Niño M., Reinoso E., 2015. Regional map of earthquake-induced liquefaction hazard using the lateral spreading displacement index DLL, 77, 1595-1618.

Juang C.H., et al., 2002. Assessing Probability-based Methodsfor Liquefaction Potential Evaluation. Journal of geotechnical and Geoenvironmental Engineering, 128(7), 580-589.

Juang C.H., Yang S.H., Yuan H., Fang S.Y., 2005. Liquefaction inthe Chi-Chi earthquake: effect of fines and capping non-liquefiablelayers. Soils and Foundations, 45(6), 89-101.

Juang C.H., Li D.K., 2007. Assessment of liquefaction hazards in Charleston quadrangle South Carolina. Engineering Geology, 92, 59-72. Doi:10.1016/j.enggeo.2007.03.003.

Juang C.H., Chang Y.O., Lu C.C., Luo Z., 2010. Probabilistic framework for assessing liquefactionhazard at a given site in a specified exposure timeusing standard penetration testing. Canadian Geotechnical Journal, 47(6), 674-687. https://doi.org/10.1139/T09-127.

Seed H.B., and Idriss I.M., 1971. Simplified procedure for evaluatingsoil liquefaction potential. Journal of the Soil Mechanics andFoundations Division, ASCE, 97(9), 1249-1273.

Vu Thanh Tam (Project Manager), 2014. Study and propose a reasonable threshold for preventing the subsidence caused by ground water exploitation, pilot application for downtown area of the Hanoi city. Final report of the Scientific research and technology development Project, National Center for water resource planning and investigation. Ministry of Natural Resources and Environment.

Nguyen Ngoc Thuy (Project manager), 2004. "Study, supplement and enhancement of the 1:25,000 scale 
Vietnam Journal of Earth Sciences, 40(1), 78-96

seismic microzonning map of the expanded Hanoi city, development of the ground motion characteristics database in Hanoi in accordance with the map". Final report of the scientific research project, The Hanoi Institute of Building Technology. Hanoi Construction Department.

Whitman R.V., Anagnos T., Kircher C.A., Lagorio H.J., Lawson R.S., Schneider P., 1997. Development of a national earthquake loss estimation methodology. Earthquake Spectra, 13(4), 643-661.

Nguyen Dinh Xuyen, 1987. Manifestation of strong earthquake activity in the territory of Vietnam, J. Sci. of the Earth, 9(2), 14-20 (in Vietnamese).

Nguyen Dinh Xuyen, Nguyen Ngoc Thuy et al., 1996. Completion of the seismic microzoning map of 1:25 000 scale for Hanoi region. Final report of the City's level project. Institute of Geophysics, Hanoi (in Vietnamese)

Nguyen Dinh Xuyen (Project Manager) 2004. Final report of the National scientific research project on
"Study of earthquake prediction and ground motion in Vietnam", Institute of Geophysics, Hanoi (in Vietnamese).

Youd T.L., Idriss I.M., Andrus R.D., Arango I., Castro G., Christian J.T., Dobry R., Finn W.D.L., Harder L.F., Hynes M.E., Ishihara K., Koester J.P., Liao S.S.C., Marcurson III W.F., Marti G.R.,Mitchell J.K., Moriwaki Y., Power M.S., Robertson P.K., Seed R.B., Stokoe II K.H., 2001. Liquefaction resistance of soils: summary report from the 1996 NCEER and 1998 NCEER/NSFworkshops on evaluation of liquefaction resistance of soils. Journalof Geotechnical and Geoenvironmental Engineering, ASCE, 127(10), 817-833.

Yuan H., Yang S.H., Andrus R.D., Juang C.H., 2004. Liquefaction-inducedground failure: A study of the Chi-Chi earthquake cases. Engineering Geology, 71(1-2), 141-155. 